\title{
How to remove the influence of trace water from the absorption spectra of SWNTs dispersed in ionic liquids
}

\author{
Juan Yang ${ }^{*}$, Daqi Zhang and Yan Li ${ }^{*}$
}

\section{Full Research Paper}

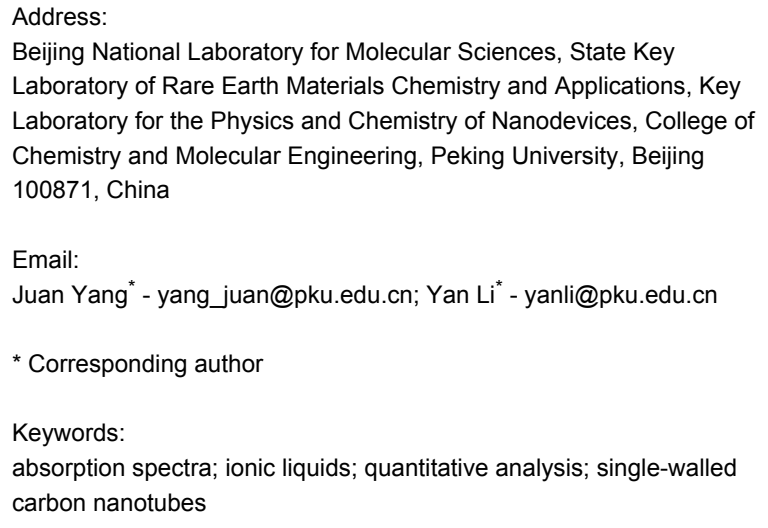

Beijing National Laboratory for Molecular Sciences, State Key Laboratory of Rare Earth Materials Chemistry and Applications, Key Laboratory for the Physics and Chemistry of Nanodevices, College of Chemistry and Molecular Engineering, Peking University, Beijing 100871, China

Email:

Juan Yang ${ }^{*}$ - yang_juan@pku.edu.cn; Yan Li - yanli@pku.edu.cn

* Corresponding author

Keywords:

absorption spectra; ionic liquids; quantitative analysis; single-walled carbon nanotubes

Beilstein J. Nanotechnol. 2011, 2, 653-658.

doi:10.3762/bjnano.2.69

Received: 30 June 2011

Accepted: 16 September 2011

Published: 30 September 2011

This article is part of the Thematic Series "Nanophotonics, nano-optics and nanospectroscopy".

Guest Editor: A. J. Meixner

(c) 2011 Yang et al; licensee Beilstein-Institut.

License and terms: see end of document.

\begin{abstract}
Single-walled carbon nanotubes (SWNTs) can be efficiently dispersed in the imidazolium-based ionic liquids (ILs), at relatively high concentration, with their intrinsic structure and properties retained. Due to the hygroscopicity of the ILs, water bands may be introduced in the absorption spectra of IL-dispersed SWNTs and cause problems in spectral deconvolution and further analysis. In order to remove this influence, a quantitative characterization of the trace water in $[\mathrm{BMIM}]^{+}\left[\mathrm{PF}_{6}\right]^{-}$and $[\mathrm{BMIM}]^{+}[\mathrm{BF}]^{-}$was carried out by means of UV-vis-NIR absorption spectroscopy. A simple yet effective method involving spectral subtraction of the water bands was utilized, and almost no difference was found between the spectra of the dry IL-dispersed SWNT samples treated under vacuum for 10 hours and the spectra of the untreated samples with subtraction of the pure water spectrum. This result makes it more convenient to characterize SWNTs with absorption spectra in the IL-dispersion system, even in the presence of trace amount of water.
\end{abstract}

\section{Introduction}

The so-called room-temperature ionic liquids (ILs) are a group of room-temperature molten salts that are composed of specific cations and anions [1,2]. Compared to conventional volatile organic solvents, they are nonpolluting, recyclable green solvents with remarkable physical and chemical properties, including low melting points, nondetectable vapor pressure, excellent stability, etc. [1-3]. In addition, by varying the structures of the component cations or anions the properties of ILs can be easily adjusted. Due to all the above advantages, ILs have attracted significant attention in many research areas such as electrochemistry [4,5], and chemical reactions and separations [6-9]. 
In 2003, Fukushima et al. [10] found that by mixing together and mechanically grinding the single-walled carbon nanotubes with imidazolium-based ILs, a thermally stable bucky gel can be formed with SWNTs untangled from the heavily entangled bundles. Since the poor solubility and low dispersibility of SWNTs in conventional solvents have hindered the processing and applications of SWNTs for more than a decade, this phenomenal discovery showed a new direction for the dispersal of SWNTs with high concentrations ( $\sim 1 \mathrm{wt} \%$ ), which are about two or three orders of magnitude higher than other suspension methods, including surfactant dispersion [11,12], DNA wrapping [13,14], polymer wrapping [15], and sidewall covalent functionalization $[16,17]$. As it does not involve any rigorous sonication, centrifugation, or chemical reaction, the structure of the SWNTs is not damaged. Moreover, a previous study [18] has shown that the electronic structure and properties of SWNTs are retained since there is no strong interaction, but only weak van der Waals interaction, between SWNTs and ILs. Therefore, imidazolium-based ILs are ideal media for the investigation of the properties and applications of SWNTs.

As it is well known that ILs are hygroscopic and that the amount of water absorbed in ILs can significantly affect the physical properties, such as polarity, viscosity, conductivity, and solubility [19-21], much research [21,22] have been carried out to study the states of water dissolved in ILs at the molecular level in order to achieve better understanding of ILs. It was found that the up-taken water interacts strongly through hydrogen bonding with the anions of the ILs, and for 1-butyl-3methylimidazolium $\left([\mathrm{BMIM}]^{+}\right)$-based ILs, $\left[\mathrm{BF}_{4}\right]^{-}$provides stronger interactions than $\left[\mathrm{PF}_{6}\right]^{-}$and more water is absorbed in $[\mathrm{BMIM}]^{+}\left[\mathrm{BF}_{4}\right]^{-}$than in $[\mathrm{BMIM}]^{+}\left[\mathrm{PF}_{6}\right]^{-}[22]$.

In the case of IL-dispersed SWNTs, the presence of water not only changes the properties of the IL but also affects the spectroscopic characterization of the dispersed SWNTs. The optical transitions of SWNTs occur when the energy of the incident radiation matches the energy gap between the van Hove singularities of SWNTs. For HiPco samples, in which the diameter of the nanotubes is about $0.7-1.1 \mathrm{~nm}$, the $\mathrm{E}_{11}$ and $E_{22}$ transitions of the semiconducting nanotubes are in the ranges of $850-1600 \mathrm{~nm}$ and $600-800 \mathrm{~nm}$, respectively, while the $E_{11}$ transitions of the metallic nanotubes are of $400-650 \mathrm{~nm}$ [23]. As the $E_{11}$ transitions of semiconducting nanotubes are of the lowest energy and do not overlap with higher energy transitions, the deconvolution of the absorption bands in this region with respect to their chiralities is of great importance in the quantitative analysis of bulk SWNT samples. However, because water has strong absorption bands in the near-infrared (NIR) region where the $\mathrm{E}_{11}$ of semiconducting SWNTs lies, even a trace amount of water dissolved in an IL may introduce notable peaks in the SWNTs absorption spectra, which will affect the deconvolution and quantitative analysis significantly. Therefore, treatment of the ILs under high vacuum, immediately before taking the spectra, is necessary to reduce the peaks introduced by the trace amount of water. Even so, the water bands are still inevitable because ILs will absorb water from the atmosphere during the period of time it takes to collect the spectra. In order to correct for the influence of water in the absorption spectra of SWNTs dispersed in ILs and furthermore to avoid an inconvenient sample treatment procedure, a simple but effective method is needed.

In this paper, a study of the UV-vis-NIR spectra of [BMIM] $]^{+}$ based ILs with different amounts of added water is described, and a quantitative characterization of the spectra with respect to the water concentrations is made. A spectral-subtraction method is used to remove the water bands from the absorption spectra of IL-dispersed SWNTs and the results are compared with the corresponding spectra of water-free samples. The exact amount of water taken up in the untreated sample is calculated consequently.

\section{Experimental}

The $[\mathrm{BMIM}]^{+}\left[\mathrm{PF}_{6}\right]^{-}$and $[\mathrm{BMIM}]^{+}\left[\mathrm{BF}_{4}\right]^{-}$ILs were purchased from Henan Lihua Pharmaceutical Co. Ltd., China. The as-received ILs were first treated under $10^{-5} \mathrm{~Pa}$ vacuum for $10 \mathrm{~h}$ to remove the absorbed water. Different amount of water (produced by Millipore SimPak 1, resistivity $\geq 18.2 \mathrm{M} \Omega \mathrm{cm}$ ) was then added to the dry ILs through a microsyringe. The water concentrations were calculated by the volume of added water and the weights of the dry ILs.

The SWNT suspensions in ILs were prepared by mechanically grinding $\sim 0.1 \mathrm{mg}$ HiPco SWNTs and $\sim 8.0$ g untreated ILs together in an agate mortar for $20 \mathrm{~min}$. The as-prepared samples ("untreated" samples) were used directly for spectral measurements. As comparison, the mixtures were then treated under $10^{-5} \mathrm{~Pa}$ vacuum for $10 \mathrm{~h}$ and the corresponding spectra of the "dry" samples were collected with dehydrates present in the sample chamber to maximally avoid the absorption of water vapor from the atmosphere.

The UV-vis-NIR absorption spectra were collected in a cell with a $1.0 \mathrm{~cm}$ path length with a PerkinElmer Lambda 950 spectrophotometer. A scan rate of $140 \mathrm{~nm} / \mathrm{min}$ with a step size of $0.5 \mathrm{~nm}$ was typically used. The spectra for ILs were recorded in the 300-2000 $\mathrm{nm}$ region while those for SWNTs-ILs were measured in the $300-1800 \mathrm{~nm}$ region. The program Origin 8.0 was used for data analysis. 


\section{Results and Discussion}

Figure 1 illustrates the UV-vis-NIR spectra of $[\mathrm{BMIM}]^{+}\left[\mathrm{PF}_{6}\right]^{-}$ with a water concentration of $0.266 \mathrm{M}$, where dry $[\mathrm{BMIM}]^{+}\left[\mathrm{PF}_{6}\right]^{-}$is used as a reference and thus its absorption is subtracted out automatically. The blue spectrum is a 20 -times magnification of the red original spectrum in order to enlarge the weak signals. Since HiPco SWNTs only show absorption bands up to $1800 \mathrm{~nm}$, it is the $300-2000 \mathrm{~nm}$ spectral region that we are most interested in. The negative bands below $450 \mathrm{~nm}$ and in the spectral region of $1600-1750 \mathrm{~nm}$ are due to the absorption of $[\mathrm{BMIM}]^{+}\left[\mathrm{PF}_{6}\right]^{-}$, which was previously reported [22].

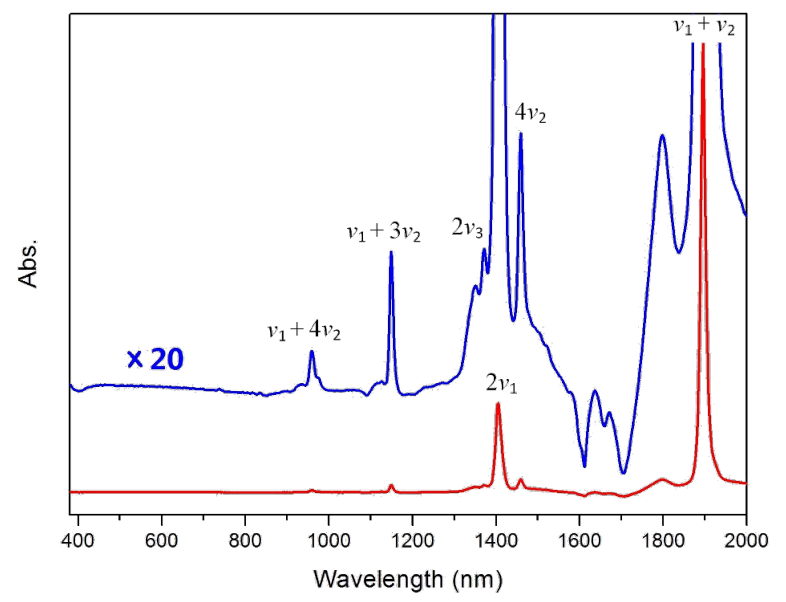

Figure 1: The UV-vis-NIR spectra of water in $[\mathrm{BMIM}]^{+}\left[\mathrm{PF}_{6}\right]^{-}$with dry $[\mathrm{BMIM}]^{+}\left[\mathrm{PF}_{6}\right]^{-}$used as a reference. The blue spectrum is a 20 -times magnification of the red original spectrum in order to enlarge the weak signals.

In the water spectra two main features are observed at 1405 and $1896 \mathrm{~nm}$, and can be attributed to the first overtone of the $\mathrm{O}-\mathrm{H}$ symmetric stretching vibration $\left(2 v_{1}\right)$ and the combination of the $\mathrm{O}-\mathrm{H}$ symmetric stretching and the angle bending vibrations $\left(v_{1}\right.$ $\left.+v_{2}\right)$, respectively. The weak band at $1372 \mathrm{~nm}$ is assigned as the first overtone of the $\mathrm{O}-\mathrm{H}$ antisymmetric stretching vibration $\left(2 v_{3}\right)$. Thus the three fundamental vibrations of water in $[\mathrm{BMIM}]^{+}\left[\mathrm{PF}_{6}\right]^{-}$can be calculated as $v_{1}=3559 \mathrm{~cm}^{-1}, v_{2}=$ $1715 \mathrm{~cm}^{-1}$, and $v_{3}=3644 \mathrm{~cm}^{-1}$, respectively. These numbers match very nicely with other bands in the spectra at 1460,1149 , and $959 \mathrm{~nm}$, with the assignments as $4 v_{2}, v_{1}+3 v_{2}$, and $v_{1}+4 v_{2}$, respectively. The $v_{1}+2 v_{2}$ band is expected to be at $1431 \mathrm{~nm}$ but is not observed in the spectra. It may be that it is covered by the much more intense band at $1405 \mathrm{~nm}$.

It is well known that for free water molecules the three fundamental vibrational frequencies are $v_{1}=3652 \mathrm{~cm}^{-1}, v_{2}=$ $1595 \mathrm{~cm}^{-1}$, and $v_{3}=3756 \mathrm{~cm}^{-1}[24]$. In $[\mathrm{BMIM}]^{+}\left[\mathrm{PF}_{6}\right]^{-}$, water interacts strongly with the $\left[\mathrm{PF}_{6}\right]^{-}$anion through hydrogen bonding and the structure of water is changed consequently, which leads to the vibrational frequency shifts. In particular, due to the hydrogen bonding between the $\mathrm{H}$ atom in water and the $\mathrm{F}$ atom in $\left[\mathrm{PF}_{6}\right]^{-}$, the $\mathrm{O}-\mathrm{H}$ bonds are weakened, and thus the two stretching vibrations move to lower wavenumbers, as expected. The angle bending vibration, on the other hand, shifts to higher frequency because of the increased force constant arising from a more rigid $\mathrm{H}-\mathrm{O}-\mathrm{H}$ structure in the presence of hydrogen bonding.

The strength of the interactions between ILs and water depends mainly on the anions, therefore, ILs with different types of anions have different influence on the structural changes of the water molecule. The absorption spectra of water in $[\mathrm{BMIM}]^{+}\left[\mathrm{BF}_{4}\right]^{-}$is shown in Figure 2, in which the blue spectrum is again the 20-times magnification of the red original spectrum. From the $2 v_{1}, 2 v_{3}$, and $v_{1}+v_{2}$ bands observed at 1416,1383 , and $1906 \mathrm{~nm}$ the corresponding fundamental vibrational frequencies of water can be calculated as $v_{1}=3531 \mathrm{~cm}^{-1}$, $v_{2}=1716 \mathrm{~cm}^{-1}$, and $v_{3}=3615 \mathrm{~cm}^{-1}$, respectively. The lower $\mathrm{O}-\mathrm{H}$ stretching and slightly higher $\mathrm{H}-\mathrm{O}-\mathrm{H}$ bending vibrational frequencies suggest stronger interactions of water with $[\mathrm{BMIM}]^{+}\left[\mathrm{BF}_{4}\right]^{-}$than with $[\mathrm{BMIM}]^{+}\left[\mathrm{PF}_{6}\right]^{-}$.

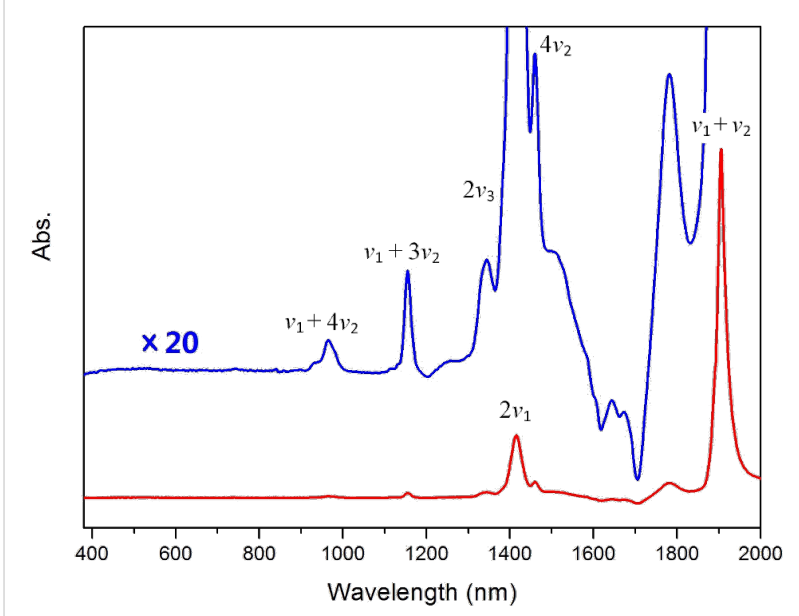

Figure 2: The UV-vis-NIR spectra of water in $\left[\mathrm{BMIM}^{+}\left[\mathrm{BF}_{4}\right]^{-}\right.$with dry $[\mathrm{BMIM}]^{+}\left[\mathrm{BF}_{4}\right]^{-}$used as reference. The blue spectrum is a 20 -times magnification of the red original spectrum in order to enlarge the weak signals.

In Figure 3a the absorption bands at $1405 \mathrm{~nm}$ with different amounts of water $(0.000,0.075,0.086,0.159,0.171$, and $0.266 \mathrm{M}$ ) added to the dry $[\mathrm{BMIM}]^{+}\left[\mathrm{PF}_{6}\right]^{-}$are plotted. It is clear that with the increased water concentration the band intensity increases concomitantly. After intensity normalization, all five bands exhibit identical frequency and shape, as shown in Figure $3 b$, indicating that the molecular state of water does not change in the experimental concentration range. The diagram of 
band intensity versus water concentration is plotted in the inset of Figure 3a and is fitted by a linear relationship. The intercept is fixed to be zero during the iteration and the resulting linear function is given by

$$
A=0.7966 c
$$

where $A$ is the absorbance at $1405 \mathrm{~nm}$ and $c$ is the water molar concentration (in M) in $[\mathrm{BMIM}]^{+}\left[\mathrm{PF}_{6}\right]^{-}$. An $R^{2}$ of 0.99993 indicates excellent linear relationship between $A$ and $c$. Although the peak areas are suppose to be used in the spectral fitting, the peak intensities could be used instead in this case because both the band shape and position remain unchanged.
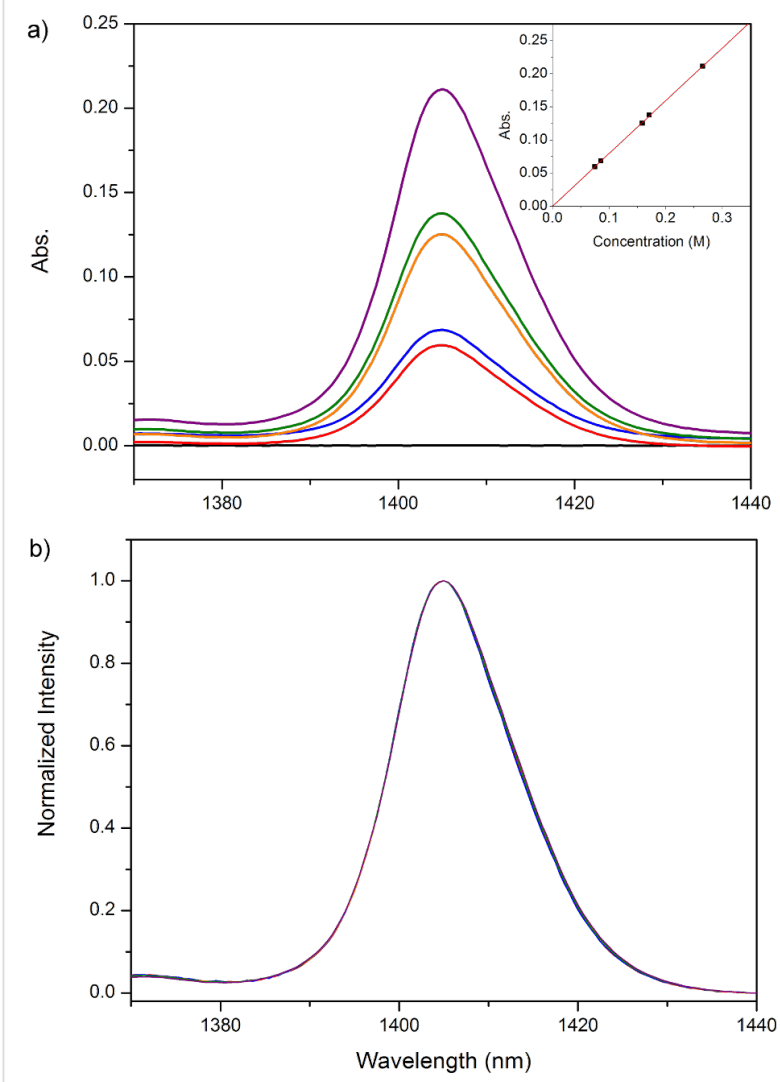

Figure 3: a) The absorption bands at $1405 \mathrm{~nm}$ with different amounts of water (from bottom to top: $0.000,0.075,0.086,0.159,0.171$, and $0.266 \mathrm{M})$ added to dry $[\mathrm{BMIM}]^{+}\left[\mathrm{PF}_{6}\right]^{-}$. The inset plots the linear fitting of band intensity vs. water concentration. b) Intensity normalization of spectra in a).

The absorption spectrum of the untreated $[\mathrm{BMIM}]^{+}\left[\mathrm{PF}_{6}\right]^{-}$dispersed SWNTs is shown as the black curve in Figure 4, with arrows indicating where the water peaks lie. The well-resolved electronic absorption bands of SWNTs demonstrate good dispersion of nanotubes in this IL. The intensity of the water band at $1405 \mathrm{~nm}$ is even higher than that of the nanotube absorption bands, so the deconvolution of the two broad bands close to $1400 \mathrm{~nm}$ with respect to semiconducting nanotube chiralities will be affected significantly by this intense water band. In order to remove this effect as well as to quantify the amount of water taken up by the untreated sample, a spectral subtraction method was utilized. To obtain the best fit with the spectrum of the water-free sample, given by the red curve in Figure 4, a specific multiplying parameter was used to scale the water spectrum in Figure 1, which was then subtracted from the spectrum of the untreated sample, the result of which is given by the blue curve. It is clearly shown in Figure 4 that not only the intense band at $1405 \mathrm{~nm}$ but also other weak bands can be subtracted out from the spectra at the same time with this bestfitting parameter. The excellent agreement of the blue and red curves verifies the feasibility of this spectral-subtraction method. The water concentration in the untreated sample can be calculated from Equation 1 as $0.0304 \mathrm{M}$ and the corresponding amount of water taken up is $6.40 \times 10^{3} \mathrm{ppm}$.

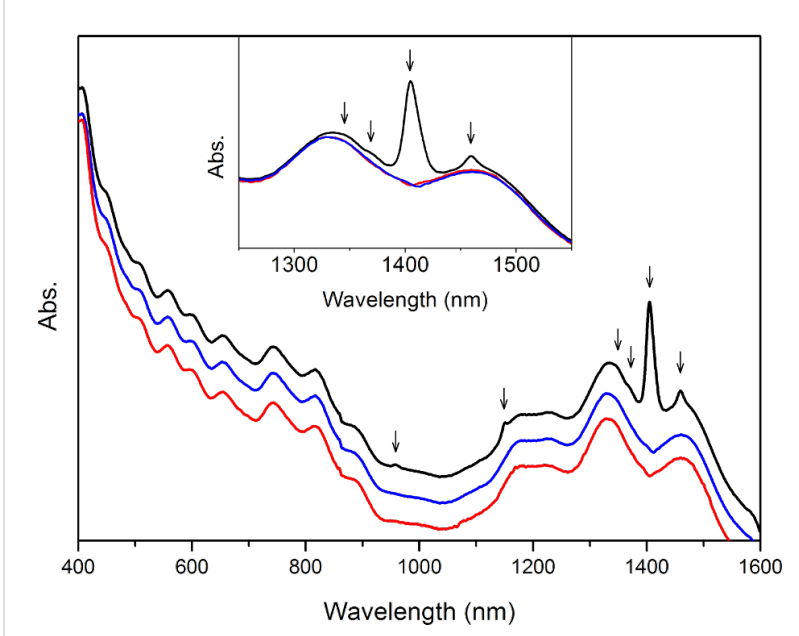

Figure 4: Absorption spectra of $[\mathrm{BMIM}]^{+}\left[\mathrm{PF}_{6}\right]^{-}$-dispersed SWNTs without treatment (black curve), after subtraction of water spectrum (blue curve), and treated under vacuum for 10 hours (red curve). The spectra are offset arbitrarily in the vertical direction for clarity. The inset shows the partially enlarged spectra. Arrows indicate the positions of water bands.

After removal of the water bands from the absorption spectra of SWNTs dispersed in $[\mathrm{BMIM}]^{+}\left[\mathrm{PF}_{6}\right]^{-}$, further analysis of the spectra can be carried out to obtain quantitative information about the bulk SWNT samples. As an example, Figure 5 illustrates the deconvolution of the baseline-corrected spectra in the $\mathrm{E}_{11}$ transition region of the semiconducting nanotubes, with the solid black curve as the baseline-corrected spectrum, the dashed red curve as the fitting spectrum, and the solid red curves as the deconvoluted individual peaks corresponding to different chiralities of the semiconducting nanotubes, as indicated in the figure. Compared to surfactant SDS-dispersed 
HiPco SWNTs [23], an average of $30 \mathrm{meV}$ red-shift in energy is observed in the semiconducting nanotube $\mathrm{E}_{11}$ region and this can be attributed to changes in the surrounding dielectric environment caused by $[\mathrm{BMIM}]^{+}\left[\mathrm{PF}_{6}\right]^{-}$.

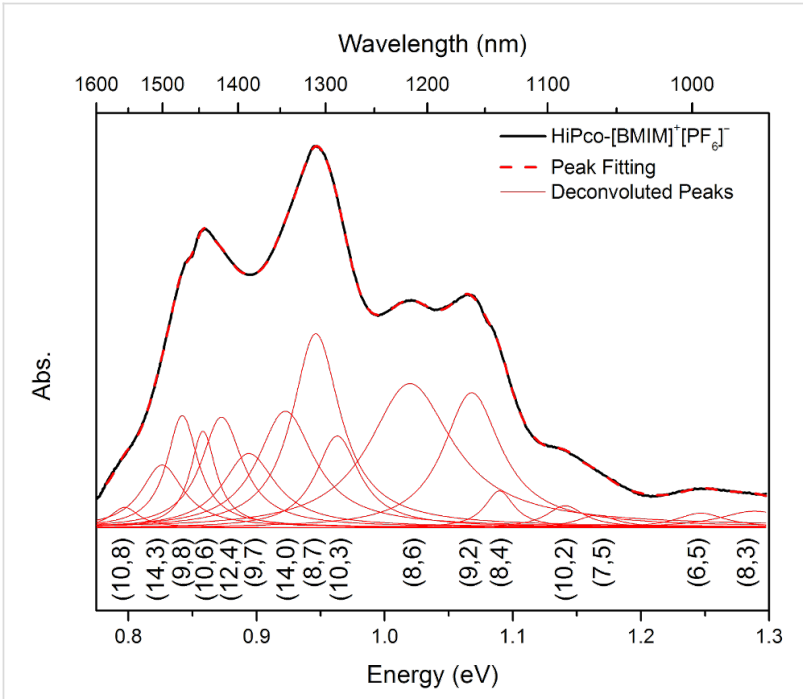

Figure 5: Deconvolution of the baseline-corrected absorption spectra of $[\mathrm{BMIM}]^{+}\left[\mathrm{PF}_{6}\right]^{-}$-dispersed SWNTs in the semiconducting nanotube $\mathrm{E}_{11}$ region with the solid black curve denoting the baseline-corrected spectrum, the dashed red curve denoting the fitting spectrum, and the solid red curves denoting the deconvoluted individual peaks corresponding to different chiralities of the semiconducting nanotubes.

A similar spectral-subtraction method was carried out with SWNTs dispersed in $[\mathrm{BMIM}]^{+}\left[\mathrm{BF}_{4}\right]^{-}$and the resulting spectra are plotted in Figure 6. The agreement of the spectrum after

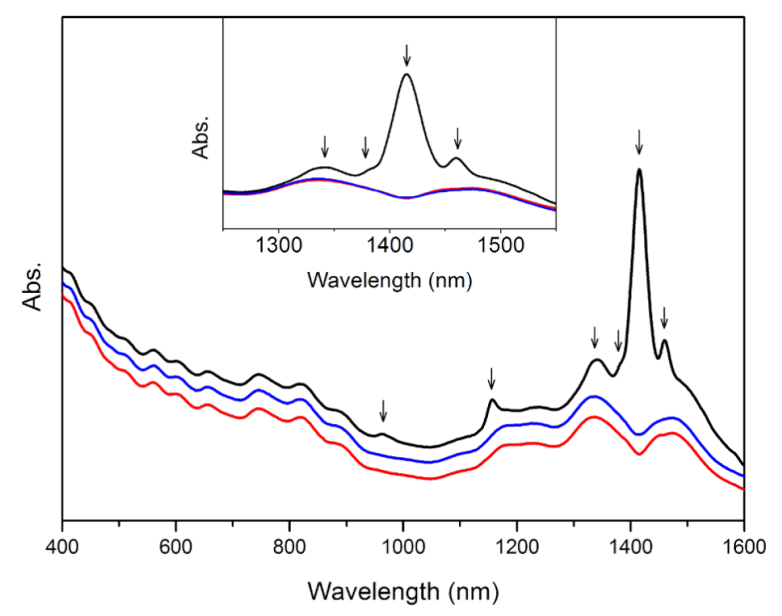

Figure 6: Absorption spectra of $\left[\mathrm{BMIM}^{+}\left[\mathrm{BF}_{4}\right]^{-}\right.$-dispersed SWNTs without treatment (black curve), after subtraction of water spectrum (blue curve), and treated under vacuum for 10 hours (red curve). The spectra are offset arbitrarily in the vertical direction for clarity. The inset shows the partially enlarged spectra. Arrows indicate the positions of water bands. subtraction of water with that of the water-free sample is also excellent, indicating the validity of this method for different types of ILs.

\section{Conclusion}

In this paper we have demonstrated a simple yet effective method for the spectral subtraction of the influence of trace water taken up by the ILs $[\mathrm{BMIM}]^{+}\left[\mathrm{PF}_{6}\right]^{-}$and $[\mathrm{BMIM}]^{+}\left[\mathrm{BF}_{4}\right]^{-}$ on the absorption spectra of IL-dispersed SWNTs. The resulting spectra are in very good agreement with the spectra of waterfree samples treated under high vacuum for $10 \mathrm{~h}$. By utilizing this spectral-subtraction method, the additional step of sample treatment under vacuum can be avoid. The spectra after subtraction can be used directly for deconvolution and further quantitative analysis. This makes the characterization of SWNTs by analysis of absorption spectra more convenient in the IL-dispersion system.

\section{Acknowledgement}

The authors would like to thank NSF (Project 21005004), SRFDP of China, and MOST (Project 2011CB933003) of China for support.

\section{References}

1. Welton, T. Chem. Rev. 1999, 99, 2071-2084. doi:10.1021/cr980032t

2. Visser, A. E.; Swatloski, R. P.; Rogers, R. D. Green Chem. 2000, 2, 1-4. doi:10.1039/a908888a

3. Huddleston, J. G.; Rogers, R. D. Chem. Commun. 1998, 1765-1766. doi:10.1039/a803999b

4. Compton, D. L.; Laszlo, J. A. J. Electroanal. Chem. 2002, 520, 71-78. doi:10.1016/S0022-0728(01)00747-1

5. Quinn, B. M.; Ding, Z.; Moulton, R.; Bard, A. J. Langmuir 2002, 18, 1734-1742. doi:10.1021/la011458x

6. Visser, A. E.; Swatloski, R. P.; Reichert, W. M.; Griffin, S. T.; Rogers, R. D. Ind. Eng. Chem. Res. 2000, 39, 3596-3604. doi:10.1021/ie000426m

7. Seddon, K. R. J. Chem. Technol. Biotechnol. 1997, 68, 351-356. doi:10.1002/(SICI)1097-4660(199704)68:4<351::AID-JCTB613>3.0.CO ;2-4

8. Baker, S. N.; Baker, G. A.; Kane, M. A.; Bright, F. V. J. Phys. Chem. B 2001, 105, 9663-9668. doi:10.1021/jp0103528

9. Song, C. E.; Shim, W. H.; Roh, E. J.; Lee, S.; Choi, J. H. Chem. Commun. 2001, 1122-1123. doi:10.1039/b101140p

10. Fukushima, T.; Kosaka, A.; Ishimura, Y.; Yamamoto, T.; Takigawa, T.; Ishii, N.; Aida, T. Science 2003, 300, 2072-2074. doi:10.1126/science.1082289

11. Islam, M. F.; Rojas, E.; Bergey, D. M.; Johnson, A. T.; Yodh, A. G. Nano Lett. 2003, 3, 269-273. doi:10.1021/nl025924u

12. Moore, V. C.; Strano, M. S.; Haroz, E. H.; Hauge, R. H.; Smalley, R. E.; Schmidt, J.; Talmon, Y. Nano Lett. 2003, 3, 1379-1382. doi:10.1021/nl034524j

13. Zheng, M.; Jagota, A.; Semke, E. D.; Diner, B. A.; McLean, R. S.; Lustig, S. R.; Richardson, R. E.; Tassi, N. G. Nat. Mater. 2003, 2, 338-342. doi:10.1038/nmat877 
14. Zheng, M.; Jagota, A.; Strano, M. S.; Santos, A. P.; Barone, P.; Chou, S. G.; Diner, B. A.; Dresselhaus, M. S.; McLean, R. S.; Onoa, G. B.; Samsonidze, G. G.; Semke, E. D.; Usrey, M.; Walls, D. J. Science 2003, 302, 1545-1548. doi:10.1126/science.1091911

15. Star, A.; Stoddart, J. F.; Steuerman, D.; Diehl, M.; Boukai, A.; Wong, E. W.; Yang, X.; Chung, S.-W.; Choi, H.; Heath, J. R. Angew. Chem., Int. Ed. 2001, 40, 1721-1725. doi:10.1002/1521-3773(20010504)40:9<1721::AID-ANIE17210>3.0.CO ;2-F

16. Bahr, J. L.; Yang, J.; Kosynkin, D. V.; Bronikowski, M. J.; Smalley, R. E.; Tour, J. M. J. Am. Chem. Soc. 2001, 123, 6536-6542. doi:10.1021/ja010462s

17. Holzinger, M.; Abraham, J.; Whelan, P.; Graupner, R.; Ley, L.; Hennrich, F.; Kappes, M.; Hirsch, A. J. Am. Chem. Soc. 2003, 125, 8566-8580. doi:10.1021/ja029931w

18. Wang, J.; Chu, H.; Li, Y. ACS Nano 2008, 2, 2540-2546. doi: $10.1021 / \mathrm{nn} 800510 \mathrm{~g}$

19. Kazarian, S. G.; Briscoe, B. J.; Welton, T. Chem. Commun. 2000, 20, 2047-2048. doi:10.1039/b005514j

20. Aki, S. N. V. K.; Brennecke, J. F.; Samanta, A. Chem. Commun. 2001, 413-414. doi:10.1039/b008039j

21. Cammarata, L.; Kazarian, S. G.; Salter, P. A.; Welton, T. Phys. Chem. Chem. Phys. 2001, 3, 5192-5200. doi:10.1039/b106900d

22. Tran, C. D.; De Paoli Lacerda, S. H.; Oliveira, D. Appl. Spectrosc. 2003, 57, 152-157. doi:10.1366/000370203321535051

23. Strano, M. S.; Dyke, C. A.; Usrey, M. L.; Barone, P. W.; Allen, M. J.; Shan, H.; Kittrell, C.; Hauge, R. H.; Tour, J. M.; Smalley, R. E. Science 2003, 301, 1519-1522. doi:10.1126/science.1087691

24. Vinogradov, S. N.; Linnel, R. H. Hydrogen Bonding; Reinhold Publishing Group: New York, 1971.

\section{License and Terms}

This is an Open Access article under the terms of the Creative Commons Attribution License (http://creativecommons.org/licenses/by/2.0), which permits unrestricted use, distribution, and reproduction in any medium, provided the original work is properly cited.

The license is subject to the Beilstein Journal of Nanotechnology terms and conditions:

(http://www.beilstein-journals.org/bjnano)

The definitive version of this article is the electronic one which can be found at: doi:10.3762/bjnano.2.69 